\title{
Safety and effectiveness of MRE in comparison with CTE in diagnosis of adult Crohn's disease
}

\author{
Majid Davari ${ }^{1}$, Abbas Keshtkar ${ }^{2}$, Elaheh Sadat Sajadian*3, Alireza Delavari ${ }^{4}$, Rashin Iman ${ }^{1}$ \\ Received: 13 Oct 2018 \\ Published: 11 Dec 2019
}

\begin{abstract}
Background: Crohn's disease (CD) is a chronic inflammatory disease of the gastrointestinal tract that is characterized by recurrent attacks and frequent recovery. The lifelong course of this disease requires frequent assessment of the disease activity. The aim of this study was to compare the effectiveness and safety of computed tomography enterography (CTE) to magnetic resonance enterography (MRE) in adults with CD.

Methods: A systematic review of the literatures was performed to evaluate the effectiveness and safety of CTE in comparison with MRE. PubMed, Cochrane Library, Scopus, Web of Science, and Embase were searched. Effectiveness outcomes included were sensitivity, specificity, diagnosis difference, diagnostic odds ratio, and positive and negative likelihood. Quality assessment of the studies was conducted using the QADAS score. Meta-analysis was done by RevMan 5.3 for selected outcomes.

Results: Five studies had eligibility for analyzing effectiveness. The meta-analysis results showed that diagnosis difference of MRE and CTE, for diagnosing active CD (0.03 CI 95\% -0.07-0.13), fistula (-0.01 CI 95\% -0.09-0.07), and cramping (-0.02 CI 95\% -0.1$0.06)$ were not statistically significant. Six studies were finally selected for safety assessment. The results showed that people who are examined with CTE frequently are at increased risk of developing cancer significantly, as they receive more than 50 msv of radiation per year.

Conclusion: There was no significant difference between MRE and CTE in diagnosis of Crohn's activity, detection of bowel obstruction, and detection of fistula and stenosis of the alimentary canal. However, the assessment of the safety profile of MRE and CTE showed that MRE is meaningfully safer than CTE for evaluating the recurrence of CD.
\end{abstract}

Keywords: Magnetic resonance enterograph, Computed tomography enterography, Crohn disease, Radiation, $50 \mathrm{mSv}$

Conflicts of Interest: None declared

Funding: This work was financially supported by Tehran University of Medical Sciences

*This work has been published under CC BY-NC-SA 1.0 license.

Copyright $\subseteq$ Iran University of Medical Sciences

Cite this article as: Davari M, Keshtkar A, Sajadian ES, Delavari A, Iman R. Safety and effectiveness of MRE in comparison with CTE in diagnosis of adult Crohn's disease. Med J Islam Repub Iran. 2019 (11 Dec);33:132. https://doi.org/10.47176/mjiri.33.132

\section{Introduction}

Crohn's disease (CD) is a chronic inflammatory disease of the digestive tract that is characterized by recurrent

\footnotetext{
Corresponding author: Elaheh Sadat Sajadian,ess16095@gmail.com
}

1. Department of Pharmacoeconomics and Pharmaceutical Administration, Faculty of Pharmacy, Tehran University of Medical Sciences, Tehran, Iran

2. Health Equity Research Center, Tehran University of Medical Sciences, Tehran, Iran

3. Student Research Committee, Principal Moderator, School of Public Health, Tehran

University of Medical Sciences, Tehran, Iran

4. Faculty of Medicine, Tehran University of Medical Sciences, Tehran, Iran attacks and frequent recovery. The prevalence of this disease has increased in Western countries, Eastern Europe,

\section{$\uparrow$ What is "already known" in this topic:}

Crohn disease (CD) is characterized by recurrent attacks. Two common diagnostic methods, computed tomography enterography (CTE) and magnetic resonance enterography (MRE) are used to diagnose and follow-up CD activity. CTE is equipped with special $\mathrm{X}$-ray radiation and can increase the risk of cancer. However, MRE has no X-ray radiation.

\section{$\rightarrow$ What this article adds:}

No significant difference was found between MRE and CTE in the diagnosis of Crohn's activity. Patients, who are examined with CTE frequently, receive more than $50 \mathrm{msv}$ of radiation per year and are at the risk of developing cancer significantly. Therefore, MRE is much safer than CTE for evaluating the recurrence of $\mathrm{CD}$. 
Asia, and developing countries since the Second World War (1). Although the prevalence of this disease is still unknown in Iran, recent studies have shown that the incidence of this disease is increasing in recent years (2). CD could cause death rarely, but it causes morbidity and disability frequently, especially in young patients. Since this group of patients have a high potential for growth, education, and productivity, their disease can negatively affect the economic dimensions of the society significantly (3).

Given the specific nature of CD, including its chronicity, recurrence, frequency, and difficulty of access to the small bowel, it is necessary to evaluate the disease activity frequently. Thus, the safety and effectiveness of the diagnostic methods are crucial $(4,5)$. Imaging techniques such as computed tomography enterography (CTE) and magnetic resonance enterography (MRE) are used to diagnose $\mathrm{CD}$. The main purpose of imaging is to detect the disease early; it can also help to identify the presence and severity of the disease and to evaluate the response of the treatment and extraintestinal complications.

CTE offers superior small bowel visualization. It uses special x-ray equipment and can increase the risk of cancer slightly (6). MRE uses a magnetic field to create detailed images that provide multidimensional photos (7). Its advantages are creating detailed imaging with the highcontrast resolution to evaluate the small bowel in CD patients with no radiation exposure $(5,6)$. Nonetheless, some of the MRE's limitations such as taking a long time for imaging, less availability, and expensive price have caused doctors to prescribe CTE more. However, since the imaging of the bowel of CD patients is highly important for $\mathrm{CD}$ management, the evaluation of effectiveness and safety of CTE and MRE is highly important.

Thus, the aim of this systematic review was to evaluate the effectiveness and safety of MRE compared to CTE in adult patients with $\mathrm{CD}$ or adults suspected with $\mathrm{CD}$.

\section{Methods}

A systematic review of the electronic databases, including the PubMed, Cochrane Library, Scopus 'Web of Science, and Embase (Appendix 1), up to August 2016 was done to evaluate the effectiveness and safety of the MRE and CTE in CD patients. A structured questionnaire was used to extract the data. Based on the structured questionnaires, keywords, possible combinations, and search strategy were determined. Then, a structured search was performed in the listed databases. The target population was adults with suspected CD. The intervention and its comparator were MRE and CTE diagnostic tests, respectively. Our favorite outcomes were sensitivity, specificity, diagnostic odds ratio, and positive and negative correlation ratio. Also, prospective studies that assessed the diagnostic accuracy of MRE and CTE were searched to assess CD activity in adult $C D$ patients or adults suspected with $C D$.

Also, a manual search was conducted in key magazines in the field of CD. A standard extraction form was prepared for data extraction. The extracted data included (1) type of study and methods, (2) patients' attributes (number, age, and gender), (3) the characteristics of the disease, (4) diagnostic interventions, and (5) outcomes. Two coau- thors extracted the data independently (E.S.S. and R.I.); and in the case of any disagreement, the third author (M.D.) made the decision, and this was according to inclusion criteria.

No limitation was considered in this search strategy; however, only English language studies were included in the final selection. The quality of the selected studies was assessed by the Quality Assessment of Diagnostic Accuracy Studies (QUADAS) (Appendix 2) tool by 2 independent authors. This 14-item checklist has been designed to assess the quality of the diagnostic studies. In this study, quality was not used as a criterion for exclusion but it was considered in the final result.

Information of the National Medical Device Directorate was used to assess the safety of MRE and CTE. In addition, a review was conducted in PubMed to find any relevant safety studies on MRE and CTE.

A Meta-analysis was done using RevMan 5.3 for all of the effectiveness outcomes. Also, a meta-analysis was done for effectiveness outcomes.

\section{Results}

Figure 1 shows the process of identifying the search for texts, removing duplicates, screening by title, abstract, and full-text. The literature search yielded 1784 eligible articles, of which 63 were selected to be reviewed in full-text and 186 patients in 5 studies were eventually selected for analysis. All studies were prospective. The summary of the characteristics of the studies are presented in Table 1.

All studies were prospective. The summary of the characteristics of the studies are presented in Table 1.

Five studies were qualified for inclusion, and Meta-Disc was performed to analyze sensitivity and specificity of diagnosing Crohns' disease. The RevMan software was used for meta-analysis of outcome of effectiveness such as fistula, stenosis of the alimentary canal, and detection of the disease activity.

\section{Detection difference of Crohn's activity between CTE} and MRE

The levels of CD activation in the 5 selected studies were reported quantitatively. Therefore, the risk difference method was used for analyzing these levels. Also, MantelHaenszel method was used for weighting. To calculate the total effect, the modified risk ratio values were used. Moreover, to measure heterogeneity in these studies, $\mathrm{I}^{2}$ parameters and the chi-two tests were applied. The value of $\mathrm{I}^{2}$ was $18 \%$. Since the value of this index was less than $30 \%$, the degree of heterogeneity was low, according to the Cochrane guide book. In addition, the value of $\mathrm{chi}^{2}$ indicated that the homogeneity in these studies was good. Thus, the fixed effects method was used to analyze the results. The results are presented in Figure 2.

This fixed model showed that the risk difference in detecting CD activation was 0.03 in these 5 studies. In other words, it showed no significant difference between the risk differences of MRE and CTE. Also, the confidence intervals were 0.13 and -0.07 , respectively, and the interval also included zero, which can confirm that there was no statistically significant difference between MRE and 


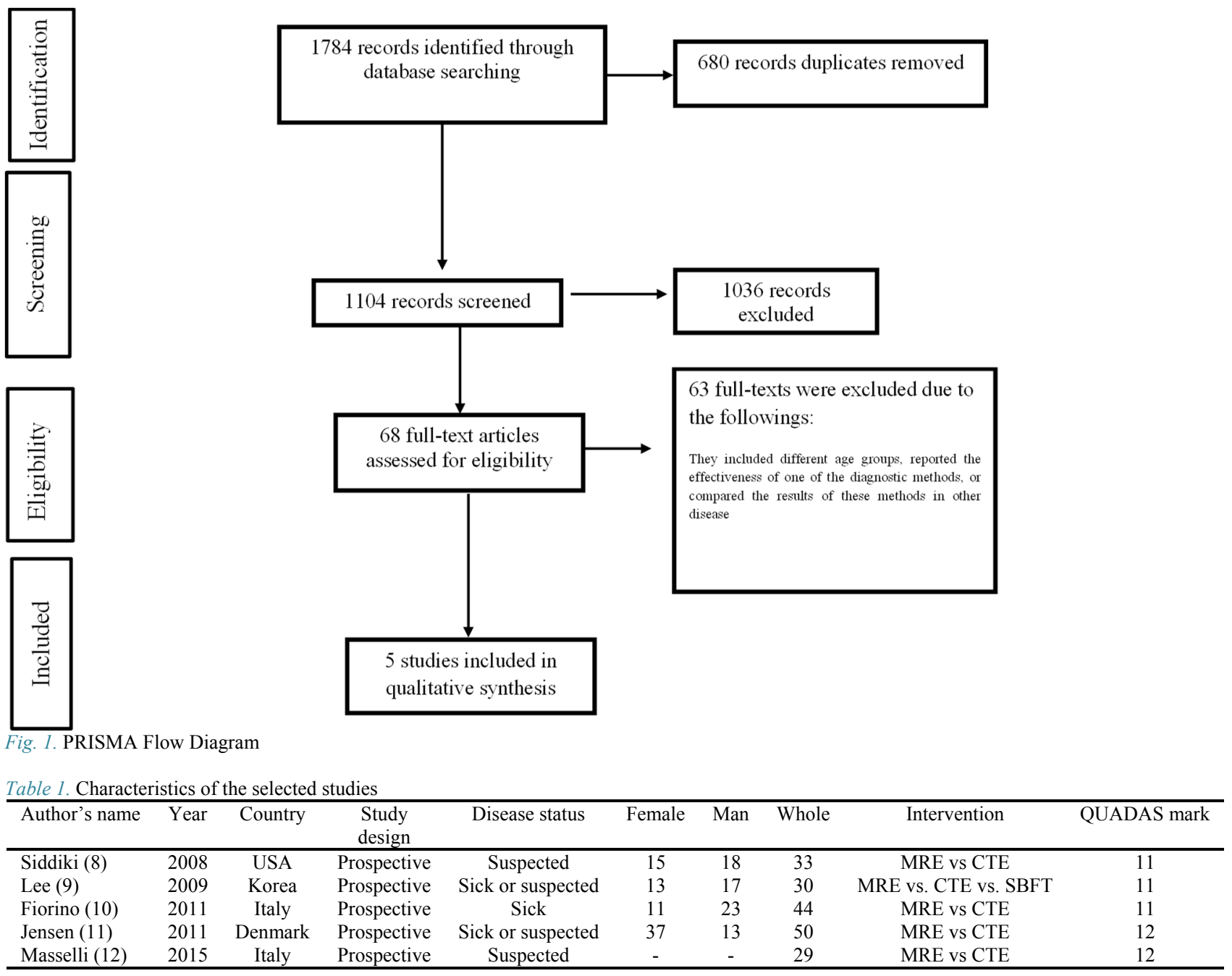

CTE in detecting CD activity with $95 \%$ confidence interval.

\section{Comparison of detection differences of fistula be- tween CTE and MRE}

To conduct meta-analysis of MRE and CTE in detecting fistula, 3 studies were finally included for analysis. The fistula detection rate was reported quantitatively. Therefore, the risk difference of the methods was used for anal- ysis. Also, Mantel-Haenszel method was used for weighing the modified risk ratio values to calculate the total effect. Moreover, to measure heterogeneity in these studies, $\mathrm{I}^{2}$ parameters and the $\mathrm{chi}^{2}$ tests were used. The value of $\mathrm{I}^{2}$ was considered zero. Since the value of this index is less than $30 \%$, it can be stated that the degree of heterogeneity was low according to the Cochrane guide book. The results are presented in Figure 3.

This fixed model showed that the risk difference in de-

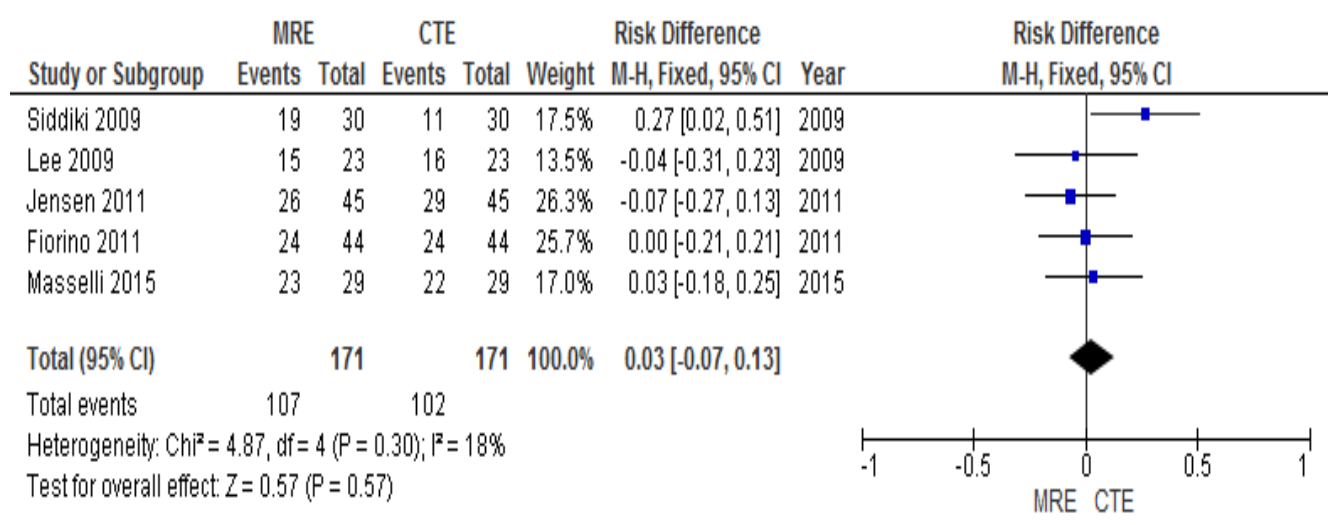

Fig. 2. Comparison of detection difference of Crohn's disease activity between CTE and MRE 




Fig. 3. Comparison of detection difference of fistula between CTE and MRE

tecting fistula in these 3 studies was -0.01. In other words, it showed no significant difference in risk difference between the 2 methods. Also, as the amount of confidence intervals was -0.09 and 0.07 , the interval included zero value, showing no statistically significant difference between the 2 methods in detecting fistula with $95 \%$ confidence interval.

Comparison of detection difference of bowel obstruction between CTE and MRE

Two studies were found to conduct meta-analysis of MRE and CTE in detecting intestinal obstruction. The detection of intestinal obstruction rate was reported quantitatively. Therefore, the risk difference method was used. Also, the Mantel-Haenszel method was used for weighing to calculate the total effect, and the modified risk ratio values were used. To measure heterogeneity in these studies, $\mathrm{I}^{2}$ parameters and the chi- 2 tests were used. The value of $\mathrm{I}^{2}$ was zero. since the value of this index was less than $30 \%$, the degree of heterogeneity was low, according to the Cochrane guide book and the value of chi-2 indicated homogeneity in these studies. Therefore, the fixed effect method was used to report the results (Figure 4).

This fixed model showed that the risk difference in detecting intestinal obstruction in 2 studies was -0.02 . In other words, it showed no significant difference between the risk difference in the 2 methods. Also, the amount of confidence intervals was -0.1 and 0.06 , and the interval included zero value. These could reveal that there was no statistically significant difference between the 2 methods in detecting intestinal obstruction with $95 \%$ confidence interval. Characteristics of the included studies for metaanalysis of diagnostic accuracy are presented in Table 2.

\section{Meta-analysis of sensitivity of MRE and CTE}

To analyze the sensitivity of MRE and CTE, 5 studies were finally included for analysis. The values of true positive, false positive, true negative, and false negative were reported in these studies.

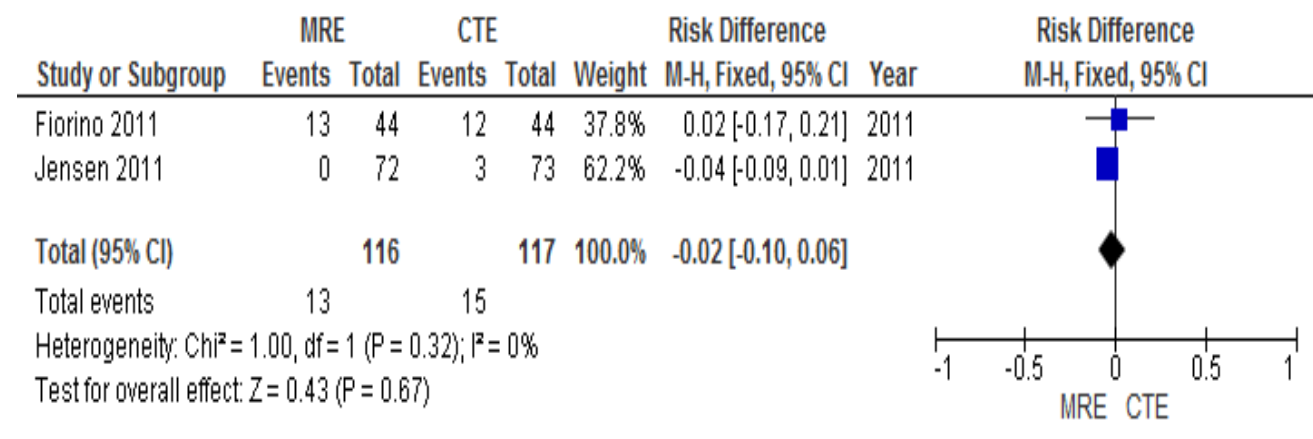

Fig. 4. Comparison of detection difference of bowel obstruction between CTE and MRE

Table 2. Characteristics of the included studies for diagnostic accuracy meta-analysis

\begin{tabular}{|c|c|c|c|c|c|c|}
\hline Tech & Studies & True positive & False positive & False negative & True negative & Total \\
\hline \multirow[t]{5}{*}{ MRE } & Lee (2009) & 15 & 0 & 3 & 5 & 23 \\
\hline & Siddiki (2009) & 19 & 3 & 2 & 6 & 30 \\
\hline & Fiorino (2011) & 24 & 0 & 4 & 16 & 44 \\
\hline & Jensen (2011) & 29 & 3 & 6 & 7 & 45 \\
\hline & Masselli (2016) & 23 & 0 & 0 & 6 & 29 \\
\hline \multirow[t]{5}{*}{ CTE } & Lee (2009) & 16 & 1 & 2 & 4 & 23 \\
\hline & Siddiki (2009) & 11 & 2 & 1 & 16 & 30 \\
\hline & Fiorino (2011) & 24 & 0 & 4 & 16 & 44 \\
\hline & Jensen (2011) & 26 & 2 & 9 & 8 & 45 \\
\hline & Masselli (2016) & 22 & 1 & 1 & 5 & 29 \\
\hline
\end{tabular}


As the heterogeneity for MRE sensitivity was $44.9 \%$ and for CTE was $34.8 \%$ (both more than $30 \%$ ), a randomeffects meta-analysis was done using DerSimonian and Laird method on the pooled sensitivity for MRE and CTE. It was observed that the value of pooled sensitivity analysis of MRE and CTE was 0.88 and 0.85 , respectively. The 0.88 sensitivity for MRE demonstrated that the power of the test was high for diagnosis of true CD patients and was higher than CTE.

\section{Meta-analysis of specificity in MRE and CTE}

For the purpose of the attribute specificity analysis, 5 studies were finally entered the analysis. The values of true positive, false positive, true negative, and false negative were reported in these studies.

The pooled specificity for MRE and CTE was calculated by the DerSimonian and Laird method, as the heterogeneity for MRE and CTE was $66.5 \%$ and $18.9 \%$, respectively (both more than $30 \%$ ). The value of pooled specificity for MRE and CTE was 0.87 and 0.89 , respectively. The 0.87 specificity for MRE indicated that although the power of MRE was high for diagnosis of true patients, the specificity of CTE was slightly higher.

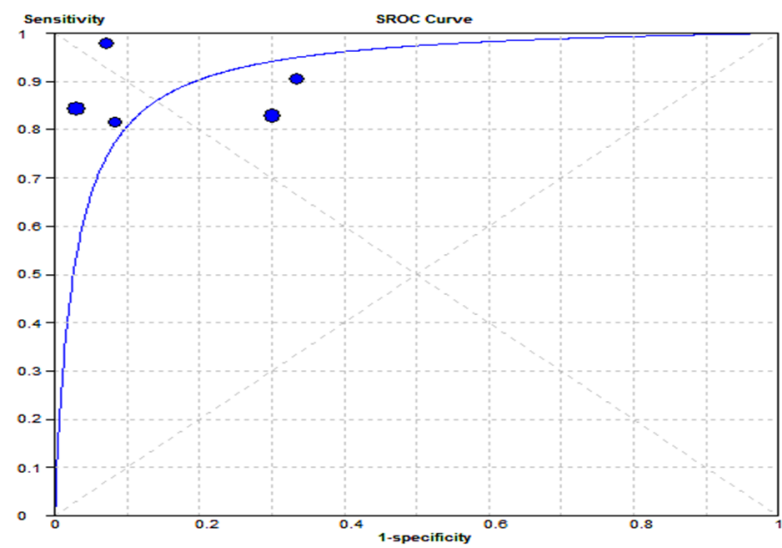

Fig. 5. ROC curve of MRE

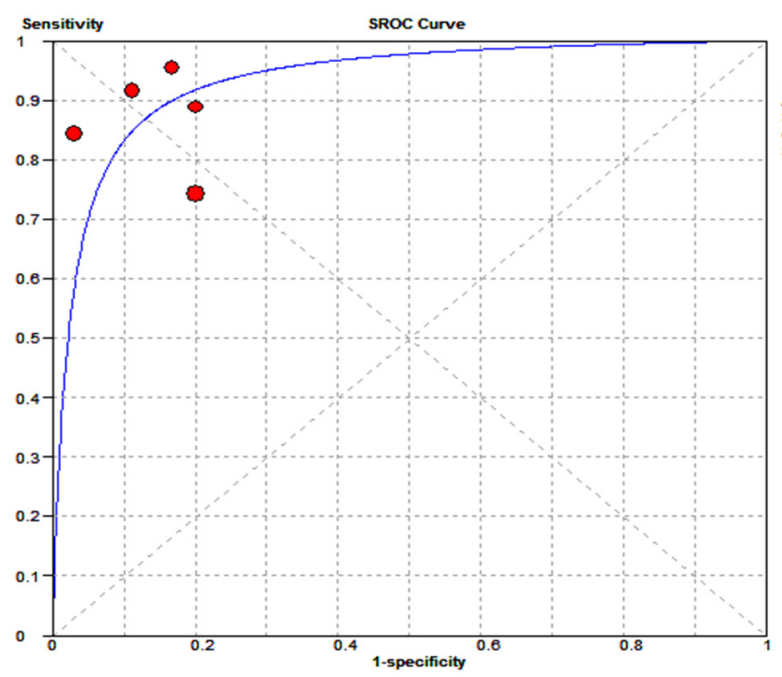

Fig. 6. ROC curve of CTE

\section{Positive likelihood ratio}

To examine the value of performing a diagnostic test, positive likelihood ratio (LR) was used in MRE and CTE tests, with the greater values showing better results.

The results of positive LR for MRE and CTE was 4.44 and 6.04 , respectively. The results showed that although both of the tests were reliable, positive LR for CTE was higher than MRE.

The negative LR for MRE and CTE was 0.16 and 0.18 , respectively. These figures also confirmed that although both methods were reliable, the value for the MRE was less than CTE.

\section{Diagnostic odds ratio}

The odds ratios greater than 1 indicate that the test is efficient in practice. Likewise, odds ratios less than 1 indicate that the test does not work efficiently. The higher value shows a better efficacy.

The meta-analyses showed that the diagnostic odds ratio of CTE was 40.58, which was higher than the diagnostic odds ratio of MRE 34.99 .

\section{Receiver operating characteristic (ROC) curve}

The receiver operating characteristic (ROC) curve was

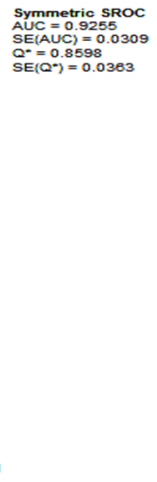


used to evaluate the performance of the diagnostic tests. Figures 5 and 6 demonstrate the ROC curve for MRE and CTE.

The ROC curve showed that the area under the curve was 0.925 . Also, the value of the index $Q$ was about 0.86 . Both values indicated the high diagnostic power of MRE. Also, the surface under the curve and the Q index for CTE was 0.934 and 0.87 , respectively. Comparing the results of rock curves confirmed that CTE has a higher diagnostic power.

\section{Results of MRE and CT safety}

To evaluate the safety of MRE and CTE, a rapid review was conducted. The keywords of computed tomography, diagnostic radiation, ionizing radiation, radiation exposure, Crohn disease, and inflammatory bowel disease were searched in PubMed database. A total of 935 articles were identified primarily. However, after assessing the eligibility of the articles, finally 6 retrospective studies were included and analyzed qualitatively.

The findings confirmed that exposure to ionizing radiation less than 50 millisieverts $(\mathrm{mSv})$ can increase the growth of solid tumors. A millisievert $(\mathrm{mSv})$ is defined as "the average accumulated background radiation dose to an individual for 1 year". However, there is no strong evidence to support this statement. Nonetheless, there is some evidence and almost a consensus that exposures to cumulative effective dose more than $\mathrm{mSv} 50<(\mathrm{CED})$ is dangerous for human bodies. This amount of radiation is equivalent to 5 abdominal and pelvic $\mathrm{CT}$ scans $(13,14)$. A comprehensive presentation and discussion of MR-related hazardous effects are beyond the scope of this review. We are exposed to natural ionizing radiation in the environment, and each time we are exposed to CT scans, it is as if we have been exposed to natural ionizing radiation for several years. Induced radiation doses of gastrointestinal imaging, compared to environmental radiation, which were extracted from radiological information $(13,14)$, are presented in Table 3.

These retrospective studies have shown that some factors such as duration of disease, severity of the disease, surgery, hospitalization, smoking, using steroids and immunosuppressive drugs, and prior surgery can cause more exposure, with cumulative effective dose more than 50 $\mathrm{mSv}$, in these patients. The characteristics of studies that evaluated safety are summarized in Table 4.

MRE is a specific type of magnetic resonance imaging which produces qualified images of the digestive tract. To date, many studies have been done on magnetic fields, but there is no evidence of harmful bioeffects produced by MRE in the long-term. Even at the field strength of 10T, no unpleasant effects have been observed in monkeys. Most studies have not shown any effect on cell growth

Table 3. Radiation dose of gastrointestinal imaging studies compared to natural radiation

\begin{tabular}{|c|c|c|c|c|c|c|}
\hline \multicolumn{3}{|c|}{$\begin{array}{l}\text { Duration of time identical to effective dose of } \\
\text { background radiation }\end{array}$} & \multicolumn{2}{|c|}{ An average effective dose } & \multicolumn{2}{|c|}{ Imaging techniques } \\
\hline 10.3 years & & & \multicolumn{2}{|l|}{31} & \multicolumn{2}{|c|}{ Several phases CT of the abdomen and pelvis } \\
\hline 3.3 years & & & \multicolumn{2}{|l|}{10} & \multicolumn{2}{|c|}{ Abdomen/pelvis CT scan } \\
\hline 3.3 years & & & \multicolumn{2}{|l|}{10} & \multicolumn{2}{|c|}{ CT scan colonography } \\
\hline 2.7 years & & & \multicolumn{2}{|l|}{8} & \multicolumn{2}{|c|}{ Abdomen CT scan } \\
\hline 1.7 years & & & \multicolumn{2}{|l|}{5} & \multicolumn{2}{|c|}{ Small intestine CT scan } \\
\hline \multicolumn{7}{|c|}{ of the selected studies fol } \\
\hline Name of study & $\begin{array}{c}\text { Number of } \\
\text { patients }\end{array}$ & Country & Design of study & $\begin{array}{l}\text { Age of popula- } \\
\text { tion }\end{array}$ & $\begin{array}{l}>\mathrm{mSv} 50 \text { Result of } \\
\text { (CED) }\end{array}$ & $\begin{array}{l}\text { Factors related to exposure } \\
\text { to high dose of radiation }\end{array}$ \\
\hline $\begin{array}{l}\text { Newnham et al } \\
2007 \text { (15) }\end{array}$ & 62 & Australia & Retrospective study & $\begin{array}{l}\text { Adult } \\
16-24 \text { years } \\
\text { old }\end{array}$ & $14.5 \%$ & $\begin{array}{l}\text { Age, duration of disease, } \\
\text { cardiac surgery, using im- } \\
\text { munosuppressive drugs }\end{array}$ \\
\hline $\begin{array}{l}\text { Butcher et al, } \\
2012(16)\end{array}$ & 280 & England & $\begin{array}{l}\text { Retrospective study of } \\
\text { Inflammatory bowel } \\
\text { disease clinic }\end{array}$ & Adult & $6.3 \%$ & $\begin{array}{l}\text { duration of disease, smoking, } \\
\text { history of surgery, heart } \\
\text { disease }\end{array}$ \\
\hline $\begin{array}{l}\text { Jung et al, } 2013 \\
\text { (17) }\end{array}$ & 777 & $\begin{array}{l}\text { South } \\
\text { Korea }\end{array}$ & $\begin{array}{l}\text { retrospective study of } \\
13 \text { hospitals of south } \\
\text { Korea }\end{array}$ & $\begin{array}{c}\text { Adult } \\
\text { Average age: } \\
29.2\end{array}$ & $34.7 \%$ & $\begin{array}{l}\text { Patient's age at diagnosis, } \\
\text { sex, history of surgery, using } \\
\text { steroid }\end{array}$ \\
\hline $\begin{array}{l}\text { Chatu et al, } 2015 \\
\text { (18) }\end{array}$ & 217 & England & $\begin{array}{l}\text { Retrospective study of } \\
\text { patient who referred } \\
\text { regularly to only so- } \\
\text { phisticated center }\end{array}$ & $\begin{array}{l}\text { Adult } \\
\text { Average age: } \\
30.8\end{array}$ & $13.36 \%$ & $\begin{array}{l}\text { history of surgery, age, signs } \\
\text { out of bowel }\end{array}$ \\
\hline $\begin{array}{l}\text { Estay et al, } 2015 \\
\text { (19) }\end{array}$ & 82 & Chile & $\begin{array}{l}\text { Retrospective study of } \\
\text { Selected patients from } \\
\text { the registry of inflam- } \\
\text { matory bowel disease }\end{array}$ & $\begin{array}{l}\text { Adult } \\
16-68 \text { years old }\end{array}$ & $19.5 \%$ & $\begin{array}{l}\text { Age, duration of disease, } \\
\text { history of surgery, Biological } \\
\text { agents in Crohn's disease, } \\
\text { site of involvement }\end{array}$ \\
\hline $\begin{array}{l}\text { Ciáurriz-Munuce, } \\
\text { et el, } 2012(20)\end{array}$ & 235 & Spain & Retrospective study & $\begin{array}{l}\text { Adult } \\
16-82 \text { years old }\end{array}$ & $20.89 \%$ & $\begin{array}{l}\text { Age more than } 40 \text { years, } \\
\text { need to surgery, age less than } \\
16 \text { at diagnosis, duration of } \\
\text { disease }\end{array}$ \\
\hline
\end{tabular}


and morphology at the field strengths up to 2T. Data reported from the National Institute for Occupational Health, World Health Organization, and the US State Department have not provided any evidence of leukemia or other malignancies due to the MRE imaging. However, the New England Journal of Medicine reported increase of leukemia in people who were exposed to electromagnetic fields in Washington from 1950 to 1979. In these cases, electromagnetic fields were caused by alternating streams leading to variable domains; also, the same effect was found in New York in 1987. However, no evidence of harmful effects was found in people who work with linear accelerators or in steady magnetic fields. However, minor and reversible effects due to magnetic fields have been observed in some studies. Metal implants produce a serious effect like torque, heat, and artifact in MRI images, so any history of surgery should be determined before MRI (21).

\section{Discussion}

The aim of this study was to determine the effectiveness and safety of MRE in comparison with CTE in adult patients with CD or suspected to have CD.

The results of the meta-analysis showed no significant difference between MRE and CTE in detecting active CD, fistula, and intestinal obstruction.

The pooled sensitivity and specificity of MRE and CTE showed that although the sensitivity of MRE was slightly higher than CTE, its specificity was lower.

The positive likelihood ratio in the diagnostic test between MRE and CTE showed that the probability of positive test for the patient was more with CTE compared to MRE. On the other hand, the negative likelihood ratio in the diagnostic test between MRE and CTE showed that the probability of negative test was less by MRE in this group.

Comparison of the diagnostic odds ratio between MRE and CTE revealed that the effectiveness of CTE was greater than MRE. Likewise, the ROC curves showed that the power of detection of CTE was higher than MRE. Nonetheless, the results confirmed that both devices have good practical efficiency in practice.

Because this review considered those studies conducted up to August 2016, another search was conducted in PubMed up to September 5, 2018. In this search, 2 related studies were found: Mitchell (22) and Wenhong Liu (23) studies. In Mitchell study, the effect of CTE and MRE were assessed in children and young people who suffered from CD in small intestine. Wenhong Liu (23) study was a systematic review of the effectiveness of magnetic resonance imaging (MRI) and computed tomography (CT) in assessing small bowel CD in different age groups. Both studies showed that CTE and MRE are good tools for diagnosing and evaluating CDs. This study showed that MRE can be a good alternative to CTE in patients with CD. Another systematic review conducted by Y. Qiu et al in 2014 (24) assessed 6 studies with 290 patients in different age groups. This study also showed that MRE had as much diagnostic power as CTE and could be a good alternative to assess CD (24). All of these studies were exclud- ed from the present study because of their populations' age groups.

The assessment of the safety of MRE and CTE showed that MRE is a safer method to evaluate the recurrence of $\mathrm{CD}$ mainly because it does not use X-ray for imaging.

The nature of $\mathrm{CD}$ is characterized by recurrence; thus, to detect the relapse of the disease frequently, all patients are required to undergo several imaging tests. The majority of the patients are young adults, and the repeated X-raybased imaging increases their exposure to harmful cumulative levels of ionizing radiation, increasing the risk of cancer. Many studies have shown that these patients will be exposed to high radiation doses more than $50 \mathrm{mSv}$, which can increase the chances of developing cancer seriously (15-20).

One of the strengths of this study was its focus on safety. The results showed that frequent X-ray imaging would cause an accumulation of harmful level of radiation, which in turn would increase the risk of cancer during the patients' lifetime. As MRE is a magnetic resonance imaging, it can produce qualified images of the digestive tract with no evidence of harmful bioeffects (21).

\section{Conclusion}

No significant difference was found between MRE and CTE in the diagnosis of CD activity, detection of bowel obstruction, and detection of fistula and stenosis of the alimentary canal. However, the assessment of the safety profile of MRE and CTE showed that MRE is meaningfully safer than CTE for evaluating the recurrence of CD. This is a highly significant result, particularly when considering the frequent use of imaging by $\mathrm{CD}$ patients and the importance of avoiding potential risk of cancer development in using CTE.

\section{Conflict of Interests}

The authors declare that they have no competing interests.

\section{References}

1. Silverberg MS, Satsangi J, Ahmad T, Arnott ID, Bernstein CN, Brant $\mathrm{SR}$, et al. Toward an integrated clinical, molecular and serological classification of inflammatory bowel disease: report of a Working Party of the 2005 Montreal World Congress of Gastroenterology. Can J Gastroentero. 2005;19 Suppl A:5a-36a.

2. Vahedi H, Merat S, Momtahen S, Olfati G, Kazazi A, Tabrizian T, et al. Epidemiologic characteristics of 500 patients with inflammatory bowel disease in Iran studied from 2004 through 2007. Arch Iran Med. 2009; 12 (5): $454-460$.

3. Naderi N, Farnood A, Minakari M, Firouzi F, Zali M. The role of genetic factors in inflammatory bowel diseases. Med Sci. 2007;17(1):51-63.

4. Kim SH. Computed tomography enterography and magnetic resonance enterography in the diagnosis of Crohn's disease. Intest Res. 2015;13(1):27-38.

5. Grand DJ, Beland M, Harris A. Magnetic resonance enterography. Radiol Clin North Am. 2013;51(1):99-112.

6. Loftus EV. Using CT and MR Enterography to Diagnose and Monitor IBD. Gastroenterol Hepatol (N Y). 2010;6(12):754-6.

7. Amitai MM, Ben-Horin S, Eliakim R, Kopylov U. Magnetic resonance enterography in Crohn's disease: a guide to common imaging manifestations for the IBD physician. J Crohns Colitis. 2013;7(8):60315 .

8. Siddiki HA, Fidler JL, Fletcher JG, Burton SS, Huprich JE, Hough 
DM, et al. Prospective comparison of state-of-the-art MR enterography and CT enterography in small-bowel Crohn's disease. AJR Am J Roentgenol. 2009;193(1):113-21.

9. Lee SS, Kim AY, Yang SK, Chung JW, Kim SY, Park SH, et al. Crohn disease of the small bowel: comparison of CT enterography, MR enterography, and small-bowel follow-through as diagnostic techniques. Radiology. 2009;251(3):751-61.

10.Fiorino G, Bonifacio C, Peyrin-Biroulet L, Minuti F, Repici A, Spinelli A, et al. Prospective comparison of computed tomography enterography and magnetic resonance enterography for assessment of disease activity and complications in ileocolonic Crohn's disease. Inflamm Bowel Dis. 2011;17(5):1073-80.

11.Jensen MD, Kjeldsen J, Rafaelsen SR, Nathan T. Diagnostic accuracies of MR enterography and CT enterography in symptomatic Crohn's disease. Scand J Gastroenterol. 2011;46(12):1449-57.

12.Masselli G, Casciani E, Polettini E, Gualdi G. Comparison of MR enteroclysis with MR enterography and conventional enteroclysis in patients with Crohn's disease. Eur Radiol. 2008;18(3):438-47.

13. Radiological Society of North America (RSNA), American college of Radiology (ACR). Radiation dose in X-ray and CT exams. Available from:URL:http://www.radiologyinfo.org/en/pdf/sfty_xray.pdfAccesse d 2015-04 .

14.Mettler FA, Jr., Huda W, Yoshizumi TT, Mahesh M. Effective doses in radiology and diagnostic nuclear medicine: a catalog. Radiology. 2008;248(1):254-63.

15.Newnham E, Hawkes E, Surender A, James SL, Gearry R, Gibson PR. Quantifying exposure to diagnostic medical radiation in patients with inflammatory bowel disease: are we contributing to malignancy? Aliment Pharmacol Ther. 2007;26(7):1019-24.

16. Butcher RO, Nixon E, Sapundzieski M, Filobbos R, Limdi JK. Radiation exposure in patients with inflammatory bowel disease-primum non nocere? Scand J Gastroenterol. 2012;47(10):1192-9.

17.Jung YS, Park DI, Kim ER, Kim YH, Lee CK, Lee SH, et al. Quantifying exposure to diagnostic radiation and factors associated with exposure to high levels of radiation in Korean patients with inflammatory bowel disease. Inflamm Bowel Dis. 2013;19(9):1852-7.

18.Chatu S, Poullis A, Holmes R, Greenhalgh R, Pollok RC. Temporal trends in imaging and associated radiation exposure in inflammatory bowel disease. Int J Clin Pract. 2013;67:1057-65.

19.Estay C, Simian D, Lubascher J, Figueroa C, O'Brien A, Quera R. Ionizing radiation exposure in patients with inflammatory bowel disease: are we overexposing our patients? J Dig Dis. 2015;16(2):83-9.

20.Ciáurriz-Munuce A, Fraile-González M, León-Brito H, VicuñaArregui M, Miquelez S, Uriz-Otano $\mathrm{J}$, et al. Ionizing radiation in patients with Crohn's disease. Estimation and associated factors. Rev Esp Enferm Dig (Madrid). 2012;104(9):452-7.

21.Westbrook C, Kaut Roth C, Talbot J. MRI in Practice, 3rd Edition. : Wiley-Blackwell 2005-06-30; 2007 12/04/2007.

22.Rees MA, Dillman JR, Anton CG, Rattan MS, Smith EA, Towbin AJ, et al. Inter-radiologist agreement using Society of Abdominal Radiology-American Gastroenterological Association (SAR-AGA) consensus nomenclature for reporting $\mathrm{CT}$ and MR enterography in children and young adults with small bowel Crohn disease. Abdom Radiol. 2019;44(2):391-7.

23.Liu W, Liu J, Xiao W, Luo G. A diagnostic accuracy meta-analysis of CT and MRI for the evaluation of small bowel Crohn disease. Acad Radiol. 2017;24(10):1216-25.

24.Qiu Y, Mao R, Chen BL, Li XH, He Y, Zeng ZR, et al. Systematic review with meta-analysis: magnetic resonance enterography vs. computed tomography enterography for evaluating disease activity in small bowel Crohn's disease. Aliment Pharmacol Ther. 2014;40(2):134-46. 
Appendix

Appendix 1. Strategy of search

PubMed

1. Crohn's* disease

2. Regional Enteritis

3. Inflammatory Bowel Disease

4. Enteritis AND Granulomatous

5. Granulomatous Enteritis

6. Enteritis AND Regional

7. Ileocolitis

8. Colitis AND Granulomatous

9. Granulomatous Colitis

10. Ileitis AND Terminal

11. Terminal Ileitis

12. Ileitis AND Regional

13. Regional Ileitis

14 . $\# 1$ or $\# 2$ or $\# 3$ or $\# 4$ or $\# 5$ or $\# 6$ or $\# 7$ or $\# 8$ or $\# 9$ or $\# 10$ or $\# 11$ or $\# 12$ or \#13

15. Magnetic resonance enterography OR MR enterography OR MRE

16. Computed Tomography Enterography OR CT Enterography OR

CTE

17. $\# 15$ or $\# 16$

18. \#14 AND \#17

Cochrane library

1. Crohn's* disease

2. Regional Enteritis

3. Inflammatory Bowel Disease

4. Enteritis and Granulomatous

5. Granulomatous Enteritis

6. Enteritis and Regional

7. Ileocolitis

8. Colitis and Granulomatous

9. Granulomatous Colitis

10. Ileitis and Terminal

11. Terminal Ileitis

12. Ileitis and Regional

13. Regional Ileitis

14. \#1 OR \#2 OR \#3 OR \#4 OR \#5 OR \#6 OR \#7 OR \#8 OR \#9 OR \#10 OR \#11 OR \#12 OR \#13

15. Magnetic resonance enterography

16. MR enterography

17. MRE

18. \#15 or \#16 or \#17

19. Computed Tomography Enterography

20. CT Enterography 22

21. CTE

22. \#19 OR \#20 OR \#21

23. \#18 OR \#22

24. \#14 AND \#23

Scopus

1. Crohn's* disease

2. Regional Enteritis

3. Inflammatory Bowel Disease

4. Enteritis AND Granulomatous

5. Granulomatous Enteritis

6. Enteritis AND Regional

7. Ileocolitis

8. Colitis AND Granulomatous

9. Granulomatous Colitis

10. Ileitis AND Terminal

11. Terminal Ileitis

12. Ileitis AND Regional

13. Regional Ileitis

14 . $\# 1$ or $\# 2$ or $\# 3$ or $\# 4$ or $\# 5$ or $\# 6$ or $\# 7$ or $\# 8$ or $\# 9$ or $\# 10$ or $\# 11$ or $\# 12$ or \#13

15. Magnetic resonance enterography OR MR enterography OR MRE

16. Computed Tomography Enterography OR CT Enterography OR CTE

17. \#15 or \#16

18. \#14 AND \#17

Web of science

1. $\mathrm{TI}=$ (Crohn's* disease OR Regional Enteritis OR Inflammatory Bowel Disease OR Granulomatous Enteritis OR Ileocolitis OR Colitis OR Granulomatous Colitis OR Terminal Ileitis OR Regional Ileitis)

2. $\mathrm{TI}=$ (Magnetic resonance enterography OR MR enterography OR MRE)

3. $\mathrm{TI}=($ Computed Tomography Enterography OR CT Enterography OR CTE)

4. \#2 OR \#3

5. \#1 AND \#4

Embase

1. Crohn's* disease/exp

2. Regional Enteritis

3. Inflammatory Bowel Disease

4. Enteritis AND Granulomatous

5. Granulomatous Enteritis

6. Enteritis AND Regional

7. Ileocolitis

8. Colitis AND Granulomatous

9. Granulomatous Colitis

10. Ileitis AND Terminal

11. Terminal Ileitis

12. Ileitis AND Regional

13. Regional Ileitis

14 . $\# 1$ or $\# 2$ or $\# 3$ or $\# 4$ or $\# 5$ or $\# 6$ or $\# 7$ or $\# 8$ or $\# 9$ or $\# 10$ or $\# 11$ or \#12 or \#13

15. Magnetic resonance enterography OR MR enterography OR MRE

16. Computed Tomography Enterography OR CT Enterography OR

CTE

17. \#15 or \#16

18. \#14 AND \#17 


\begin{tabular}{|c|c|c|c|c|}
\hline Item & & Yes & No & Unclear \\
\hline 1. & Was the spectrum of patient's representative of the patients who will receive the test in practice? & ( ) & ( ) & ( ) \\
\hline 2. & Were selection criteria clearly described? & ( ) & ( ) & ( ) \\
\hline 3. & Is the reference standard likely to correctly classify the target condition? & ( ) & ( ) & ( ) \\
\hline 4. & $\begin{array}{l}\text { Is the time period between reference standard and index test short enough to be reasonably sure that the target condition } \\
\text { did not change between the two tests? }\end{array}$ & ( ) & ( ) & ( ) \\
\hline 5. & Did the whole sample or a random selection of the sample, receive verification using a reference standard of diagnosis? & ( ) & ( ) & ( ) \\
\hline 6. & Did patients receive the same reference standard regardless of the index test result? & ( ) & ( ) & ( ) \\
\hline 7. & Was the reference standard independent of the index test (i.e. the index test did not form part of the reference standard)? & ( ) & ( ) & ( ) \\
\hline 8. & Was the execution of the index test described in sufficient detail to permit replication of the test? & ( ) & ( ) & ( ) \\
\hline 9. & Was the execution of the reference standard described in sufficient detail to permit its replication? & ( ) & ( ) & ( ) \\
\hline 10. & Were the index test results interpreted without knowledge of the results of the reference standard? & ( ) & ( ) & ( ) \\
\hline 11. & Were the reference standard results interpreted without knowledge of the results of the index test? & ( ) & ( ) & ( ) \\
\hline 12. & $\begin{array}{l}\text { Were the same clinical data available when test results were interpreted as would be available when the test is used in } \\
\text { practice? }\end{array}$ & () & () & () \\
\hline 13. & Were uninterpretable/ intermediate test results reported? & () & () & ( ) \\
\hline 14. & Were withdrawals from the study explained? & ( ) & () & () \\
\hline
\end{tabular}

